\title{
Advances in the diagnosis and management of chronic pulmonary aspiration in children
}

\author{
R.P. Boesch*,\#, C. Daines*,\#, J.P. Willging*, , A. Kaul*,+, A.P. Cohen ${ }^{\S}$, \\ R.E. Wood*,\# and R.S. Amin*,\#
}

ABSTRACT: Chronic pulmonary aspiration (CPA) in children is an important cause of recurrent pneumonia, progressive lung injury, respiratory disability and death. It is sporadic, intermittent and variable, and often occurs in children with complicated underlying medical conditions and syndromes that produce symptoms indistinguishable from CPA. For most types of aspiration there is no gold-standard diagnostic test. The diagnosis of CPA is currently made clinically with some supporting diagnostic evaluations, but often not until significant lung injury has been sustained. Despite multiple diagnostic techniques, the diagnosis or exclusion of CPA in children is challenging. This is of particular concern given the outcome of unrecognised progressive lung injury and the invasiveness of definitive therapies.

Although new techniques have been introduced since the 1990s and significant advances in the understanding of dysphagia and gastro-oesophageal reflux have been made, characterisation of the aspirating child remains elusive.

KEYWORDS: Aspiration, bronchoscopy, children, fibreoptic-endoscopic evaluation of swallowing, oesophageal impedance

hronic pulmonary aspiration (CPA) represents the repeated passage of food material, gastric refluxate, and/or saliva into the subglottic airways in a manner sufficient to cause chronic or recurrent respiratory symptoms. These symptoms include chronic cough, wheeze, recurrent pneumonia, failure to thrive, choking on feeds or secretions, and radiological signs of chronic lung injury [1-5]. CPA is sporadic and intermittent, and in some children may only occur coincidentally with other stressors, such as an upper respiratory tract infection. CPA often occurs in children with complicated underlying medical conditions and syndromes that produce similar respiratory symptoms. For instance, a child with chronic lung disease from pre-maturity and tracheomalacia may have recurrent cough, wheeze and atelectasis and may also chronically aspirate. Anatomic abnormalities that create a direct connection between the oesophagus and airway result in CPA. While tracheo-oesophageal fistulas are often apparent at birth, h-type fistulas or laryngo-oesophageal clefts may be more difficult to detect. Other craniofacial abnormalities may also disrupt the coordination between swallowing and respiration, and predispose to aspiration. CPA results in progressive lung disease, bronchiectasis and respiratory failure, and is the leading cause of death in children with severe neurological disorders [6]. To date, therapeutic interventions for CPA have associated morbidity and mortality and often result in increased complexity of care for these children.

As some nocturnal aspiration of saliva and gastric refluxate occurs in normal healthy subjects $[7,8]$, but clearly results in progressive lung disease in others, the threshold of what constitutes pathological aspiration in a given individual may vary. Determining whether aspiration is a significant cause of respiratory disease can thus be challenging. There are no gold-standard diagnostic tests for CPA. Currently, the diagnosis of aspiration is made clinically with some supporting diagnostic evaluations. Owing to the complex nature of chronic aspiration, a multidisciplinary approach is optimal.

This review will present an overview of the literature regarding CPA, discussing the currently available diagnostic tests and their limitations, and management options. Management of specific anatomic causes of CPA would require its own review and, therefore, are not discusssed
AFFILIATIONS

*Aerodigestive and Sleep Center, and,

Divisions of ${ }^{\#}$ Pediatric Pulmonary Medicine,

"Pediatric Otolaryngology and Head and Neck Surgery,

+Pediatric Gastroenterology, Hepatology and Nutrition, and ${ }^{\S}$ Thoracic and Pediatric Surgery, Cincinnati Children's Hospital Medical Center, Cincinnati, OH, USA

CORRESPONDENCE

R.P. Boesch

Clinical Fellow

Pediatric Pulmonary Medicine

Cincinnati Children's Hospital

Medical Center

Cincinnati

OH 45229

USA

Fax: 15136364615

E-mail: paul.boesch@cchmc.org

Received:

November 232005

Accepted after revision:

May 202006

European Respiratory Journal Print ISSN 0903-1936 Online ISSN 1399-3003 
here. Special emphasis will be given to newer techniques and emerging diagnostic modalities designed to improve the characterisation of this elusive disease.

\section{PATHOPHYSIOLOGY}

Pulmonary aspiration may occur as a result of swallowing dysfunction, gastro-oesophageal reflux (GOR), or an inability to protect the airway adequately from oral secretions. In children with CPA, more than one mechanism is often involved and the condition may be due to structural and/or medical conditions.

\section{Aspiration due to swallowing dysfunction}

Normal swallowing is a complex process that requires the coordination of voluntary and involuntary actions. After oral acceptance and preparation, a food bolus is voluntarily delivered to the pharynx. This triggers the involuntary pharyngeal phase in which the soft palate seals the nasopharynx, the larynx is elevated and tilted anteriorly, the true and false vocal folds close and the pharyngeal constrictors sequentially contract to propel the bolus into the oesophagus. The upper oesophageal sphincter simultaneously relaxes and is pulled open to accept the bolus through laryngeal elevation. Peristalsis then transports the bolus to the stomach. An intrinsic abnormality in the effectiveness, duration, or timing of any of these components can result in aspiration. Although CPA due to swallowing dysfunction most often occurs in children with neurological disease, it should also be considered in neurologically normal infants with recurrent pneumonia, recurrent wheezing, chronic cough or stridor [9].

\section{Reflux aspiration}

Although an association between GOR and respiratory symptoms, such as wheezing, chronic cough, nocturnal cough, apnoea and recurrent lung infections, has been well documented [10-12], a causal relationship between GOR and respiratory symptoms due to CPA is difficult to determine in an individual child [13-15]. Several studies [12, 16-19] provide evidence substantiating a cause-and-effect relationship between GOR and CPA. Acid is clearly toxic to the respiratory tract. Specifically, aspiration of acidic ( $\mathrm{pH} 1-2)$ contents into the lungs has been shown to cause desquamation of mucosa, damage to alveolar lining cells and capillaries and acute neutrophilic inflammation [20]. Pulmonary aspiration of contents with $\mathrm{pH}>2.5$ has caused pneumonitis in an animal model [21]. Observational evidence suggests that medical and surgical treatment of GOR may decrease lung infections [12]. Two small adult studies of simultaneous oesophageal and tracheal $\mathrm{pH}$ monitoring have also demonstrated a temporal relationship between a drop in oesophageal $\mathrm{pH}$, tracheal $\mathrm{pH}$ and peak expiratory flow [16, 17]. Also, exposure of laryngeal mucosa to acid significantly decreases laryngeal sensation, which increases the risk of aspiration [18].

MORTON et al. [19] evaluated the relationship between GOR and recurrent lower respiratory tract infections in a group of children with cerebral palsy in a study that highlights the variable relationship between GOR and CPA. MORTON et al. [19] found that severe GOR did not increase lower respiratory infections without the coexistence of swallowing dysfunction and that even mild GOR was associated with recurrent infections in the presence of swallowing problems. Despite the evidence that GOR can cause respiratory symptoms as a result of aspiration, GOR can cause similar respiratory symptoms by other mechanisms. Stimulation of oesophagogastric reflexes can cause bronchospasm without actual penetration of stomach contents into the airway [22], which makes it difficult to determine whether or not a child with chronic respiratory symptoms and GOR is aspirating.

\section{Salivary aspiration}

Chronic aspiration of saliva is the least-commonly recognised form of aspiration and is usually not diagnosed prior to the development of significant lung injury. The oral cavity contains potentially pathogenic bacteria and yeast. These organisms can cause recurrent pneumonia or pulmonary abscess if aspirated in sufficient quantity [23]. Most neurologically impaired children who aspirate their saliva do so because of severe swallowing incoordination and absent laryngeal sensation rather than excess production of saliva [24]. In children who continue to have symptoms of aspiration despite cessation of oral feeding and treatment or diagnostic exclusion of GOR, an evaluation for salivary aspiration is warranted. In contrast, children with significant sialorrhoea; choking on secretions; severe neurological impairment; laryngotracheo-oesophageal cleft; vocal cord paralysis; coloboma, heart defects, atresia choanae, retardation of growth and development, genitourinary problems and ear abnormalities (CHARGE) association; Moebius, West or Pfeiffer syndromes; or congenital high airway obstruction syndrome (CHAOS), should undergo evaluation for salivary aspiration earlier in the diagnostic process. The current authors have found that children with these conditions have a much higher likelihood of salivary aspiration.

\section{RADIOGRAPHIC EVIDENCE OF ASPIRATION}

Plain chest radiographs and high-resolution computed tomography (HRCT) are utilised in the evaluation of children suspected of aspiration. They are not, however, considered diagnostic tests for aspiration. Rather, they are useful indicators of lung injury which may be seen in a distribution characteristic of CPA. They may also document progression or resolution of the disease process over time.

\section{Chest radiograph}

CPA typically presents radiographically as hyperaeration, subsegmental or segmental infiltrates and peribronchial thickening. Bronchiectasis may also eventually be seen. The basilar and superior segments of lower lobes as well as posterior upper-lobe segments are the most significantly involved. Chest radiographs are not sufficiently sensitive to detect the subtle changes that occur in early lung injury.

\section{HRCT}

HRCT of the chest is known to be more sensitive than plain radiographs in the detection and definition of early airway and parenchymal disease in paediatric patients $[25,26]$. In a child with a suggestive history, the combination of airway and parenchymal findings in a distribution consistent with aspiration can be interpreted as evidence of lung injury caused by CPA. HRCT can detect bronchiectasis, centrilobular opacities ("tree-in-bud"), air trapping and bronchial thickening [26, 27]. 
While these findings are not specific for CPA, they are common in children who chronically aspirate.

\section{DIAGNOSTIC PROCEDURES \\ Diagnosis of CPA due to swallowing dysfunction}

Videofluoroscopic swallow study

Videofluoroscopic swallow study (VSS) has the ability to evaluate the oral pharyngeal and oesophageal phases of swallowing directly. Any abnormalities in bolus formation or timing of swallow, as well as velopharyngeal insufficiency, can be visualised. Premature spillage of the food bolus before the swallow, residue after the swallow, penetration into the airway, aspiration into the trachea with or without cough clearance, impaired passage into the oesophagus caused by cricopharyngeal achalasia, and regurgitation of swallowed food can all be seen. A speech and language pathologist (SLP) is integral to the examination, allowing detailed feeding recommendations to be made at the time of the evaluation. The examination can be tailored to provide consistencies similar to those the child is already eating at home, and optimal feeding position and food consistency can be assessed.

VSS expands upon the bedside clinical evaluation of swallowing, which is excellent in the assessment of oral motor skills, but insufficient to assess aspiration risk accurately. A recent study [28] reported that clinical examination has a negative predictive value of $89 \%$ to predict aspiration or penetration of liquids on VSS, but a positive predictive value of only $54 \%$. The positive predictive value for clinical examination is even lower $(18 \%)$ for aspiration of solids. When swallowing abnormalities are suspected on clinical examination, VSS is generally adequate to detect those who are at risk of CPA during oral feeding and to make effective feeding and rehabilitative recommendations [29-31].

VSS also has limitations. Although feeding recommendations based on VSS have been shown to decrease lower respiratory tract infections in acutely brain-injured adults with dysphagia [30], findings in other studies have suggested that VSS may have an unacceptable false-negative rate in predicting those who will progress to have aspiration pneumonia $[32,33]$. The reliability of VSS is also variable. Multiple prospective studies [34-36] have documented poor inter- and intra-observer reliability for all components of VSS except for detection of actual aspiration events. Owing to the episodic nature of aspiration, a normal VSS cannot entirely rule out aspiration of feeds. The strengths and limitations of VSS are summarised in table 1. Generally, VSS is a standard evaluation for direct aspiration in children in whom clinical examination has revealed abnormal swallowing.

Fibreoptic-endoscopic evaluation of swallowing

Since the introduction of flexible endoscopy for the assessment of dysphagia in 1988, its use has continued to expand [37]. In the current authors' institution, fibreoptic-endoscopic evaluation of swallowing (FEES) is performed by an otolaryngologist in conjunction with an SLP. The study can be performed in children of any age and requires no sedation or exposure to radiation. A small flexible nasopharyngoscope is positioned between the soft palate and epiglottis and multiple swallows are visualised directly by the otolaryngologist, the SLP and the child's home caregivers via a video monitor. The oral and pharyngeal phases can be assessed but the scope is blind to events occurring during pharyngeal contraction. As with VSS, children can be fed the same food they are given at home, the consistencies can be varied and the effectiveness of implemented compensatory and therapeutic swallowing techniques can be assessed at the time of examination. The ability of the caregiver to observe the aspiration event as well as the effectiveness of feeding techniques directly provides strong feedback and reinforcement.

\section{Comparisons between FEES and VSS}

FEES has been found to be as sensitive as VSS at detecting delayed initiation of swallow, penetration, aspiration and postswallow residue [38, 39]. LEDER and KARAS [40] found complete agreement between the results of FEES and VSS in paediatric patients and were able to make specific feeding recommendations based on FEES. A prospective, randomised trial in dysphagic adults found no difference in pneumonia outcomes whether feeding recommendations were made based on FEES or VSS results [41]. The inter- and intra-observer reliability of FEES is similar to that of VSS [42]. FEES has not been evaluated in normal controls to determine how the presence of a nasopharyngoscope might alter the swallowing mechanism. FEES, however, has some advantages over VSS. A thorough anatomic and functional evaluation of the pharynx and larynx can be performed in a way that cannot be seen during VSS. Other advantages include portability, variability in feeding positions, and an ability to evaluate children who have severe oral aversions or who are not feeding by mouth. Aspiration risk can be evaluated in these children by assessing excessive pooling of oral secretions and laryngeal sensation or by placing a few drops of coloured food dye or chlorophyll on the tongue, and observing for aspiration or penetration [43]. Both FEES and VSS are useful and complementary owing to the different types of information they provide (table 1).

\section{Flexible bronchoscopy with bronchoalveolar lavage}

The calculation of a quantitative index of lipid-laden macrophages in bronchoalveolar lavage (BAL) samples has repeatedly been evaluated as a test for CPA of various types and conflicting results have been reported. Theoretically, an increased prevalence of lipid-filled macrophages in the lower airway suggests aspiration of food intake directly or following reflux from the stomach. An early paediatric study by COLOMBO and HALlBERG [44], in which children were classified based on clinical suspicion of aspiration during feeding, found that a lipid-laden macrophage index (LLMI) on a 0-400 scale differentiated between the two groups. All of the children suspected of aspiration had a LLMI >86; the highest LLMI in the "nonaspirator" group was 72. This is the only prospective study designed to evaluate LLMI as a marker of CPA caused by swallowing dysfunction in children. The two groups were similar in regard to chest radiography findings and respiratory symptoms and differed only as to whether or not they choked on food. GOR was not consistently evaluated in either group as a potential confounder. A retrospective study [45] attempted to overcome some of the limitations of an absent gold standard by determining chronic aspiration (of any type) by response to treatment via telephone follow-up. Patients who improved with treatment were regarded as "correctly diagnosed". Within the subset of patients correctly diagnosed, those 


\section{TABLE 1 Summary of diagnostic tests of aspiration}

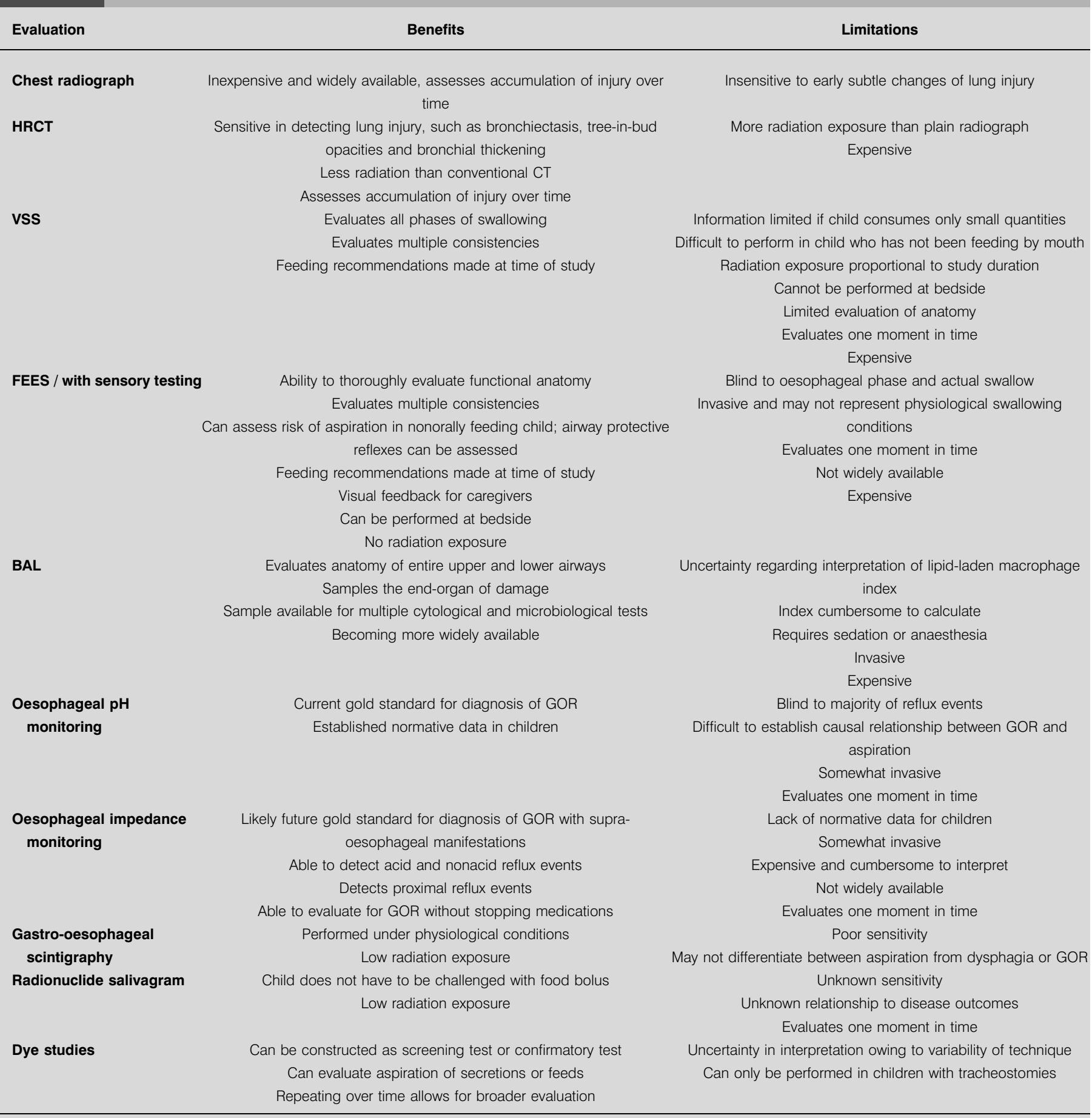

HRCT: high-resolution computed tomography; VSS: videofluoroscopic swallow study; FEES: fibreoptic-endoscopic evaluation of swallowing; BAL: bronchoalveolar lavage; CT: computed tomography; GOR: gastro-oesophageal reflux.

regarded as aspirators had a mean \pm SD (range) LLMI of $112 \pm 63$ (20-233) whereas those regarded as nonaspirators had a mean \pm SD (range) LLMI of $43 \pm 42$ (0-170). The sensitivity and specificity were 0.73 and 0.81 , respectively, for an index cut-off of 90 .
Although it seems logical that the presence of exogenous lipid in the lower airways would be an indicator of aspiration of fatcontaining material, this finding is not specific for aspiration. Using the same methodology for determining LLMI as Colombo and Hallberg [44], KNauer-Fischer and Ratjen [46] 
found high lipid indexes in children with various lung diseases. KAZACHKOV et al. [47] found the highest LLMI in patients with cystic fibrosis. Endogenous lipid from surfactant or cell membranes can also be engulfed by alveolar macrophages [48] and LLMI can be elevated by the use of i.v. lipid preparations [49], pulmonary fat embolism in sickle cell disease [50], and endogenous lipoid pneumonia from bronchial obstruction [51]. It is not possible to differentiate clearly between exogenous and endogenous lipid on a lipid stain. Table 2 illustrates the variability of the results of studies performed to evaluate the utility of a LLMI to diagnose CPA.

Further complicating the interpretation of LLMI is a reported lack of reproducibility. One study sought to formally evaluate the inter- and intra-observer reliability of two methods of calculating LLMI [55]. A biased difference between observers was found, with the difference increasing as LLMI values increased. The interobserver coefficient of variation was often $>50 \%$. An LLMI may also vary depending on the amount of time since the last aspiration event. In an animal study using rabbits [56], the LLMI remained above 75 for 2 days in animals receiving a single tracheal instillation of milk and 5 days in animals having received weekly instillations.

Despite these significant limitations, an LLMI may provide supporting evidence of aspiration in select patients. There is insufficient evidence to support the notion that an isolated finding of increased lipid in BAL is sufficient for diagnosis of aspiration, although a very large amount would be more suggestive.

\section{Diagnosis of reflux aspiration}

$\mathrm{pH} /$ Impedance monitoring

The "gold standard" for the diagnosis of GOR has been considered to be 24-h oesophageal $\mathrm{pH}$ monitoring but this may change owing to its increasingly recognised limitations. Standard $\mathrm{pH}$ monitoring is unable to recognise superimposed acid events that occur after a $\mathrm{pH}$ drop but before $\mathrm{pH}$ normalisation [57, 58]. These superimposed reflux events may represent up to $38 \%$ of acid-reflux events [57]. Also, a large proportion of GOR is nonacidic and therefore undetectable by $\mathrm{pH}$ monitoring. Nonacid reflux material can also be aspirated and cause lung disease. It is therefore unlikely that detection of acid reflux alone is adequate in the diagnostic evaluation of CPA.

Multichannel intraluminal impedance and $\mathrm{pH}$ monitoring (MII-pH) has been increasingly studied for its ability to detect both anterograde and retrograde passage of acid, nonacid and gaseous material. By measuring changes in electrical impedance at multiple levels of the oesophagus, the movement of a fluid or air bolus can be detected. The $\mathrm{pH}$ is measured simultaneously, allowing differentiation between an acidic or nonacidic bolus. MII-pH studies have found that in contrast to adults, infants with GOR have a much greater proportion of nonacid reflux than acid reflux [57-59]. These events occur most frequently within $2 \mathrm{~h}$ of a meal and are invisible to $\mathrm{pH}$ monitoring owing to buffering from the food. MII-pH is able to detect much more pharyngeal-level reflux than $\mathrm{pH}$ monitoring and, therefore, it may be more able to predict those at risk of reflux aspiration [59-62]. In one study of infants with regurgitation and respiratory symptoms, $85.7 \%$ of impedancedetected events correlated with respiratory irregularities on polysomnogram and $73 \%$ of these reached the hypopharynx [61]. Only $11.8 \%$ of events were acid and $90 \%$ were associated with oxygen desaturation to $<90 \%$. This suggests that MII-pH may become the technique of choice for evaluating supraoesophageal manifestations of GOR.

TABLE 2 Summary of evidence regarding lipid-laden macrophage index (LLMI)

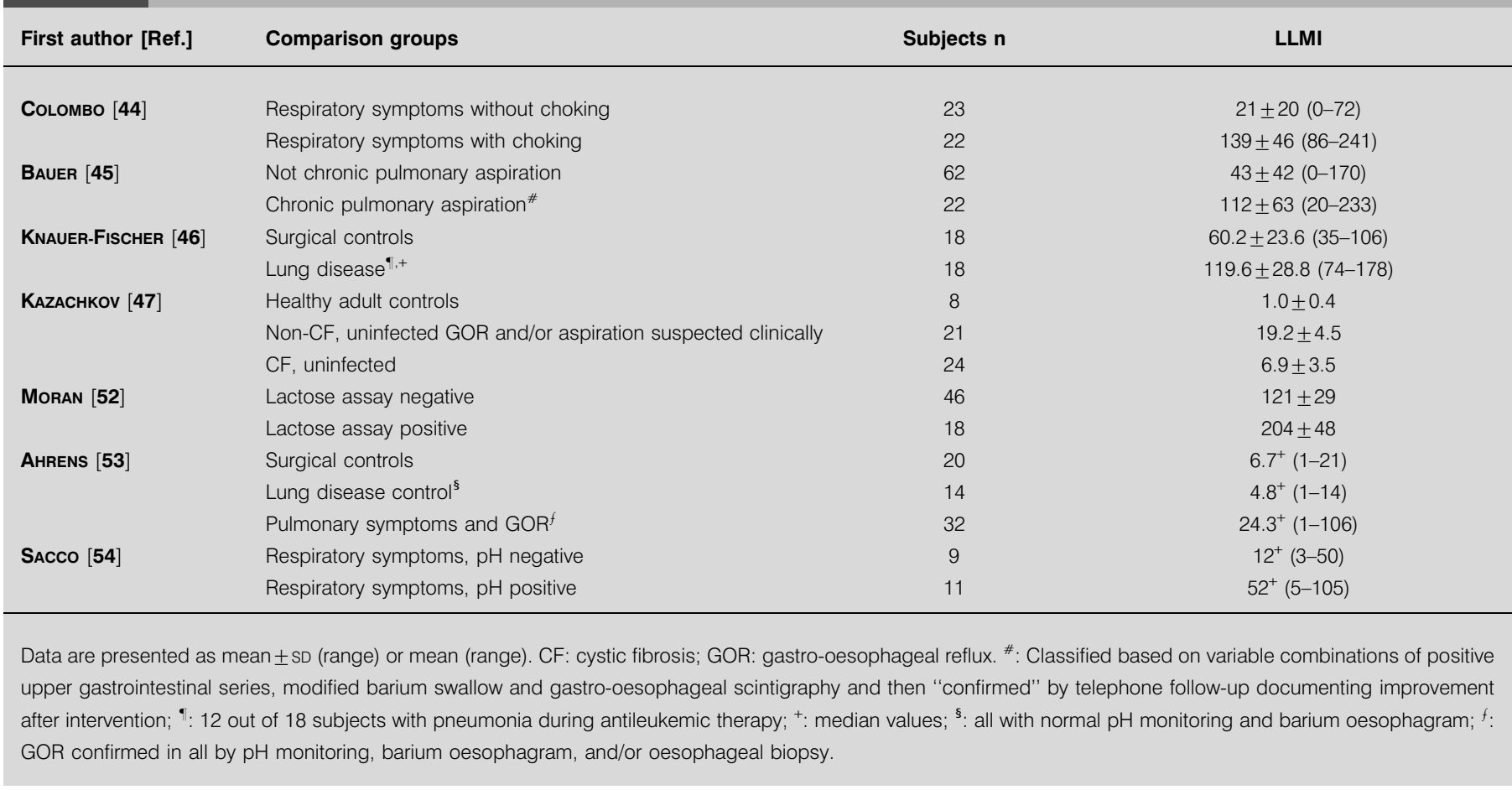


There is still much to be investigated regarding the use of oesophageal impedance as a diagnostic tool for aspiration. To date, no studies have attempted to use MII-pH to predict CPA from acid or nonacid reflux. The major limitation in the validation of $\mathrm{MII}-\mathrm{pH}$ is that although there is evolving "normal" data in adults, there is no paediatric normative data.

\section{Flexible bronchoscopy with BAL}

The use of an LLMI to determine CPA caused by reflux is even more difficult than diagnosing direct aspiration during feeding. Three prospective studies attempting to compare LLMI values in children with chronic respiratory symptoms with and without documented GOR [52-54] have shown even wider variability than studies for direct aspiration (table 2) [42-44]. The most striking limitation of these studies is study design. More specifically, these studies were designed to evaluate the ability of LLMI to detect children with GOR among a group of children with respiratory symptoms. This seems implausible owing to the multiple mechanisms by which GOR can produce respiratory symptoms. A noteworthy study by MORAN et al. [52] employed an assay of lactose in the trachea of intubated and ventilated neonates who were receiving lactose-containing orogastric feeds, and used this as confirmation of aspiration of enteral feeds. The authors found that LLMI differentiated between neonates with positive and negative assays. At an LLMI threshold of 100, they determined a sensitivity of $100 \%$, and a specificity of $22 \%$, while at a threshold of 150, sensitivity and specificity were 73 and $84 \%$, respectively. The relationship between LLMI and GOR determined by MII-pH has not been investigated, but data would be useful given the limitations of oesophageal $\mathrm{pH}$ monitoring. Currently, in a child with GOR there is insufficient evidence to support the diagnosis of reflux CPA using LLMI, largely owing to the difficulty in establishing a causal link between GOR and CPA.

\section{Gastro-oesophageal scintigraphy and barium oesophagrams}

Gastro-oesophageal scintigraphy ("milk scans") has been regarded as a physiological test for GOR and CPA [63]. Technetium-99-sulphur colloid is mixed into an infant's formula and the child is then allowed to eat ad lib. Serial images are taken in order to detect tracer activity in the lung parenchyma. This finding may signify aspiration but the technique is not able to differentiate clearly between direct aspiration and reflux aspiration. Milk scans are attractive in that there is minimal radiation exposure and, if patients are offered multiple feedings, these scans can offer a wider window of opportunity to detect aspiration. Despite these advantages, the sensitivity of a milk scan to detect aspiration is questionable [63-66]. One recent test of children with severe cerebral palsy found positive milk scans in only $6 \%$ [66]. This is quite low considering the high prevalence of both GOR and CPA in this population and the fact that VSS and salivagrams were positive in 39 and $56 \%$ of the studied patients, respectively. If other more sensitive tests are available, gastrooesophageal scintigraphy would not be an initial diagnostic test of choice for CPA. Barium oesophagrams and upper gastrointestinal series have also been used at times as tests for evaluation for GOR and/or aspiration but they are not reliable tests for either.

\section{Diagnosis of salivary aspiration}

Radionuclide salivagrams

Radionuclide salivagrams are performed by placing a small quantity of radiotracer in the buccal pouch and recording serial images until there is clearance from the mouth. The presence of activity in the trachea or bronchi indicates aspiration. This test is commonly used as it is readily available, does not challenge the patient with presentation of an oral bolus, and results in minimal exposure to radiation.

Radionuclide salivagrams are repeatedly cited as the most sensitive test for salivary aspiration despite the fact that there have been no studies to evaluate their diagnostic accuracy. Three retrospective reports [67-69] have shown a $26-28 \%$ prevalence of positive salivagrams in children suspected of aspiration, but no other confirmatory tests were performed. In one study evaluating the ability of salivagrams to predict the need for laryngotracheal separation, no correlation was found between salivagram result and days hospitalised owing to respiratory symptoms [70]. Radionuclide salivagrams show poor agreement with other tests for aspiration [66]. In contrast, one case series [71] documented the use of serial salivagrams to successfully titrate tracheal continuous positive pressure to eliminate aspiration. Further evaluation regarding the accuracy of radionuclide salivagrams is needed.

\section{FEES with sensory testing}

As mentioned above, FEES can be a very useful examination in children who are not feeding orally but continue to have symptoms of aspiration. Aspiration of oral secretions can be directly visualised or impending aspiration can be determined by the presence of pooled secretions in the larynx and diminished laryngeal sensitivity. Laryngeal sensation can be quantified by applying graded bursts of air to the aryepiglottic fold and documenting the threshold pressure required to elicit the laryngeal adductor reflex. Both pooled oral secretions and decreased laryngeal sensation predict aspiration without challenging the patient with an oral bolus [43, 72-75].

\section{Dye studies}

The suctioning of dye-stained tracheal secretions in patients with a tracheostomy who have been given dye on the tongue or mixed into feeds has been used as a test for CPA. Several authors [76-80] have compared the accuracy of dye studies with those of VSS and FEES. Three studies [76-78] have reported a false negative rate of $50-61 \%$ but specificities near $100 \%$. In these studies, foods of various consistencies for VSS or FEES were dyed blue and the tracheostomy tube was then suctioned. Dye studies of this type were noted to be sensitive in detecting children who aspirated more than trace amounts. BELAFSKY et al. [80] took a different approach. The authors utilised three administrations of dyed feeds, with tracheal suctioning $1 \mathrm{~h}$ after eating, and then performed FEES. Compared with FEES they found this dye test to have a sensitivity of $82 \%$ but a specificity of only $38 \%$. None of these studies were performed in children. Dye studies with a small volume administered may be useful as confirmatory tests when positive, and larger more frequent administrations may serve as a screening test to identify children with possible CPA. There is no evidence regarding the accuracy of this test in children. 


\section{Difficult cases}

Occasionally, children who have clinical histories suggestive of recurrent aspiration, with radiographic evidence of lung disease and increased lipid on BAL, yet who have multiple negative evaluations for swallowing dysfunction or GOR are encountered at the current authors' institution. In these children, the diagnosis of CPA due to incoordinated swallowing is made only when a trial of no feeding by mouth and nasogastric tube feeding results in improvement in respiratory symptoms. These children highlight the difficulty in establishing this diagnosis, and the importance of clinical judgment in the evaluation of children with suspected CPA.

\section{TREATMENT OPTIONS}

\section{Treatment of aspiration from swallowing dysfunction}

For dysphagic infants and children, an initial plan for feeding intervention is usually developed during a bedside clinical evaluation, VSS or FEES. Implementing compensatory strategies during these evaluations allows feedback to both physicians and caregivers regarding the effectiveness of the interventions. Compensatory strategies include positioning, pacing, thickening liquids, stimulating swallows and improving pharyngeal clearance. It is important to recognise that paediatric dysphagia is usually a mixed disorder caused by a combination of structural abnormalities, neurological conditions, cardiorespiratory problems, behavioural issues and inflammatory/metabolic disorders [81]. As such, a multidisciplinary approach utilising the expertise of SLPs, occupational therapists, dietitians, otolaryngologists, psychologists, neurologists, geneticists, surgeons, gastroenterologists and pulmonologists is often necessary.

Cricopharyngeal achalasia is a specific cause of CPA from swallowing dysfunction. Infants present with dysphagia, drooling, choking, nasal reflux and hypersalivation. The characteristic appearance on VSS is of a posterior "bar" and manometry may show high pressure at the upper oesophageal sphincter. Cricopharyngeal myotomy is the procedure of choice and may result in immediate improvement [82]. If performed early enough, cricopharyngeal myotomy may prevent disruption of coordinated swallowing.

For children who are unable to consume sufficient calories safely by mouth, percutaneous or surgical placement of a feeding gastrostomy or jejunostomy may be performed. Surgical gastrostomy tubes can be placed open, laparoscopically, percutaneously or endoscopically, with or without a fundoplication. There has been considerable debate in the literature regarding the benefit of a routine antireflux procedure at the time of gastrostomy tube placement in neurologically impaired children [83-91] (table 3). These studies show worsening or de novo development of GOR after placement of a gastrostomy in $5-67 \%$ of these children. This is not predictable by pre-procedure $\mathrm{pH}$ monitoring, biopsy or radiography. Based on these studies, $5-34 \%$ of children will eventually require antireflux surgery, primarily to control symptomatic GOR. There is little evidence that morbidity or mortality are increased in neurologically impaired children without GOR who do not undergo preventative fundoplication. This is further supported by a decision analysis study by BURD et al. [92], who were unable to demonstrate a threshold of risk at which preventative fundoplication would be favoured.
It is generally accepted that children with neurological impairment and CPA or symptomatic GOR should undergo an antireflux procedure at the time of feeding tube placement.

\section{Treatment of CPA due to GOR}

Medical and conservative therapies are initially chosen for children with GOR. There are several options. WENZL et al. [93] used MII-pH to show that thickened feeds significantly decrease the frequency and height of nonacid reflux events though not acid events. Effective prokinetic agents are limited. In the USA, metoclopramide and erythromycin are most commonly used. The efficacy of metoclopramide has not been demonstrated and side-effects may be unacceptable [94]. Erythromycin acts as a motilin against and has been investigated at anti-microbial and low doses. Clinical investigations focusing on time to tolerance of enteral feeds in premature neonates have had conflicting results [95-98], but adverse effects associated with low-dose erythromycin were not reported. Another study evaluated the effect of erythromycin on gastrointestinal motility and found a positive doseeffect relationship with antral motility, but duodenal motility was unaffected [99]. Domperidone, which is available outside the USA, has not been shown to be clearly effective for the treatment of GOR in children [100] and has not been evaluated as a treatment of reflux aspiration. Proton pump inhibitors (PPIs) have been widely used to decrease acid reflux and the perceived risks are low. Although the efficacy of PPIs has been established for oesophagitis, neither safety nor efficacy has been established for CPA. For many children with CPA due to GOR, medical therapy does not result in improvement in lower respiratory tract injury. An inadequate improvement in recurrent pneumonia is not surprising given the predominance of nonacid reflux in children.

Fundoplication has become the antireflux procedure of choice in children with persistent or severe respiratory symptoms and GOR. The outcome of fundoplication is generally good. Elimination of GOR occurs in almost all patients. Resolution or improvement of respiratory symptoms occurs in $48-92 \%$ of patients [101-104]. Four paediatric studies have specifically described the impact of fundoplication on respiratory symptoms and their results are summarised in table 4 . Recurrence of GOR occurs in $\sim 10 \%$ of patients but repeat procedures are effective in almost all patients [103, 105-108]. Unfortunately, it is in children with neurological impairment or oesophageal dysmotility that there is a greater baseline incidence of both GOR and CPA, as well as a greater likelihood of failure of fundoplication $(\sim 27 \%)[101,103,105]$. Care must be taken to identify the presence of significant oesophageal dysmotility before tightening the oesophagogastric junction, as this can result in significant accumulation of oral secretions in the oesophagus and thereby increase the risk of CPA. Even without dysmotility, a "too tight" fundoplication can create a barrier to anterograde passage and induce aspiration. Evaluation for delayed gastric emptying is also sometimes necessary; in such cases pyloromyotomy may be indicated. Since children with neurological disease and oesophageal dysmotility have an increased burden of CPA due to GOR, fundoplication should be considered when there is coexistence of GOR and recurrent lung infections. 


\begin{tabular}{|c|c|c|c|c|c|}
\hline First author [Ref.] & Study type & Pre-gastrostomy GOR excluded by & Patients & Post-operative GOR & ARS \\
\hline MoLLITT [83] & $P$ & UGI, scintigraphy and $\mathrm{pH}$ & 16 & $4(25)^{\#}$ & $4(25)$ \\
\hline JoLLey $[84]$ & $P$ & $\mathrm{pH}$ & 9 & $6(67)^{\#}$ & $3(33)$ \\
\hline LANGER [85] & $\mathrm{R}$ & UGI & 50 & $22(44)^{\bullet}$ & $17(34)$ \\
\hline Isch [88] & $\mathrm{R}$ & Symptoms, scintigraphy or UGI & 39 & $11(28)^{\pi}$ & $8(20)$ \\
\hline SULAEMAN [89] & $\mathrm{R}$ & $\mathrm{pH}$ & 22 & $5(22)^{\circ}$ & $1(5)$ \\
\hline Puntis [90] & $\mathrm{R}$ & Symptoms or $\mathrm{pH}$ & 27 & $15(56)^{\bullet}$ & $2(7)$ \\
\hline HAMENT [91] & $\mathrm{R}$ & $\mathrm{pH}$ & 59 & $3(5)^{\#}$ & \\
\hline
\end{tabular}

Data are presented as $n$ or $n$ (\%). GOR: gastro-oesophageal reflux; ARS: antireflux surgery; P: prospective; UGl: upper gastrointestinal series; R: retrospective. ${ }^{*}$ : postoperative GOR diagnosed by testing; ‘: post-operative GOR diagnosed by symptoms.

Owing to the controversy surrounding fundoplication, some authors [109, 110] recommend jejunostomy tube placement either as a primary procedure or after fundoplication failure for neurologically impaired children. Jejunostomies allow adequate feeding and may reduce respiratory infections but do not guarantee elimination of GOR and therefore significant aspiration may continue to occur. Feeding jejunostomies carry a risk of intussusception and repeated displacement, and do not allow the convenience of bolus feeding.

For children with severe neurological impairment or oesophageal atresia, a procedure for oesophagogastric separation has been described [111, 112]. This procedure allows for bolus feeding through a gastrostomy while the oesophagus connects directly to the jejunum. GOR appears to be well controlled by this procedure; however, the incidence of subsequent respiratory infections remains high. In one study [111], salivary secretion intolerance was noted by $50 \%$ of families, suggesting that aspiration of saliva may be a cause of persistent CPA. This procedure has not been extensively studied in paediatric patients, particularly with regard to safety and, therefore, consideration of a child for this procedure should be approached with caution.

\section{Treatment for aspiration of saliva}

Oral anticholinergic medications have been used in neurologically impaired children to treat the symptoms of sialorrhoea. Glycopyrrolate administered orally at $0.04-0.1 \mathrm{mg} \cdot \mathrm{kg}^{-1}$. dose $\mathrm{e}^{-1}$ appears to be effective at reducing salivation [113], but it is not known whether reduction of saliva persists beyond a few weeks. In one study [113], nine out of 27 children experienced a diminishing effect within 4 weeks. Anticholinergic treatment is frequently associated with adverse effects, which are significant enough for treatment to be discontinued in $\sim 20 \%$ of patients [113-115]. Side-effects include behavioural changes, constipation, dry mouth and secretions, urinary retention, flushing, nasal congestion, vomiting, and diarrhoea. There is concern that excessive thickening of bronchial secretions might result in atelectasis or life-threatening mucus plugging. There have been no studies on the effect anticholinergics may have on reducing CPA.

Recent clinical trials have evaluated the effectiveness of botulinum toxin in controlling sialorrhoea in children with cerebral palsy [116-118]. In a controlled clinical trial, JONGERIUS et al. [116] found that a scopolamine patch and injection of botulinum A into submandibular glands resulted in equivalent reductions of salivary production. In $49 \%$ of patients, the response was maintained through 24 weeks. In contrast, eight out of nine children in another study needed repeat injections at 1 month [118]. It is not known whether serial botulinum injections would be needed indefinitely to achieve persistent control over the long term. A near absence of adverse effects was reported across all studies (table 5). No study of the effectiveness of salivary gland injection of botulinum toxin has addressed a change in respiratory symptoms associated with CPA.

TABLE 4 Summary of studies evaluating effect of fundoplication on respiratory symptoms

\begin{tabular}{llcc} 
First authors [Ref.] & Children with medically recalcitrant GOR undergoing fundoplication & Patients & Resolution \\
\hline JolLEY [101] & Mixed group with recurrent aspiration pneumonia, choking and/or chronic cough & 61 & 92 \\
MATTIOLI [102] & Mixed group with recurrent aspiration, lower respiratory tract infections, recurrent pneumonia or & 30 & 80 \\
& chronic cough & 31 & $48^{\#}$ \\
KAWAHARA [103] & Neurologically impaired with recurrent respiratory infections or distress & 21 \\
ESPOSITO [104] & Repaired oesophageal atresia with recurrent aspiration & 86 \\
\hline
\end{tabular}

GOR: gastro-oesophageal reflux. ${ }^{\#}$ : four subjects required laryngotracheal separation, three required tracheostomy. 
TABLE 5 Summary of evaluations for control of drooling

\begin{tabular}{|c|c|c|c|c|c|}
\hline First author [Ref.] & Procedure & Patients n & Complication rate \% & $\begin{array}{l}\text { Parent-reported } \\
\text { improvement \% }\end{array}$ & Follow-up \\
\hline SAVARESE $[117]$ & Parotid botulinum & 21 & 0 & 89 & 2 months \\
\hline HASSIN-BAER [118] & Parotid botulinum & 9 & 0 & 33 & 4 months $^{+}$ \\
\hline Gerber $[119]$ & $\begin{array}{l}\text { Bilateral mandibular gland exci- } \\
\text { sion and parotid duct ligation }\end{array}$ & 16 & $19^{\circ}$ & 73 & $1 \mathrm{yr}$ \\
\hline KLEM [121] & Four-duct ligation & 5 & $0^{\circ}$ & 100 & 13 months \\
\hline SHIRLEY [122] & Four-duct ligation & 21 & $29^{\circ}$ & 81 & \\
\hline
\end{tabular}

Another potential treatment for aspiration of oral secretions involves the ligation and/or removal of salivary glands. Bilateral ligation of submandibular and parotid ducts or excision of submandibular glands with parotid duct ligation have been reported in children [119-122]. Both procedures are effective at reducing sialorrhoea (table 5). Saliva production from minor salivary glands is sufficient to prevent xerostomia. STERN et al. [120] reported persistent significant improvement in both quality of life and sialorrhoea at a mean follow-up of 4.2 yrs. Two retrospective studies $[119,121]$ have documented a significant decrease in numbers of hospitalisations and lower respiratory tract infections following the procedure. Prospective trials are needed to determine whether there is a significant benefit of surgery to improve chronic salivary aspiration and how this effect might compare with botulinum injection.

Children with CPA (particularly salivary aspiration) often receive a tracheostomy because of their underlying medical conditions and for pulmonary toilet. Multiple studies [123, 124] have suggested an association between the presence of a tracheostomy tube and impaired swallowing. The presence of a tracheostomy tube impairs laryngeal elevation during swallowing. Alterations in timing, especially during the pharyngeal phase, have been observed [123, 124]. None of these studies evaluated swallowing prior to placement of a tracheostomy. An adult study by LEDER and Ross [125] evaluated patients before and after they received a tracheostomy. The authors concluded that dysphagia was evident prior to tracheostomy in $60 \%$ of these patients and that de novo aspiration developed in only $5 \%$. To date, this has not been studied in paediatric patients.

The definitive treatment for the elimination of CPA is laryngotracheal separation or diversion [126, 127]. This procedure eliminates all continuity between the respiratory and digestive tracts by disconnecting the upper trachea from the larynx and diverting it directly to a stoma. The diversion of the proximal trachea to the oesophagus allows for drainage of pooled secreations, but carries added surgical risk due to creation of an anastomasis with the oesophagus. With a laryngotracheal seperation, the proximal trachea is simply closed and oral secreations that accumulate in the larynx are either orally expressed or swallowed. Although this procedure generally eliminates aspiration, there are a number of adverse sequelae. There is a complete loss of phonation and the child is left with a permanent tracheostomy. Frequency of tracheocutaneous fistula development ranges $0-38 \%$ [128, 129], and stenosis of the stoma site has been reported [128, 130]. Even if this procedure is performed without a complete laryngectomy, laryngotracheal separation may not be reversible.

\section{APPROACH TO DIAGNOSIS AND TREATMENT}

A diagnosis and treatment algorithm is presented in figure 1. This algorithm is based on the limited evidence available in the literature as well as on the combined experience of the subspecialists at the current authors' quarternary care institution; 400 children each year are evaluated for potential CPA. Based on the combination of presenting clinical signs and symptoms, several invasive procedures are often carried out simultaneously under a single administration of general anaesthesia. This practice has a number of advantages. It allows for an efficient evaluation of many types of aspiration; it is cost-effective; and it decreases the burden on families of multiple procedures spread out over time. Owing to the variable presentation of CPA, this approach does not apply to all patients and the limitations of each diagnostic test and therapy must be kept in mind. As no single currently available diagnostic test can entirely rule out CPA, the current authors find it necessary to repeat evaluations when the clinical picture is that of ongoing aspiration.

\section{FUTURE DIRECTIONS}

Due to the invasive nature of FEES, a novel method of assessing vocal cord motion using glottic ultrasound is being developed for the evaluation of dysphagia [130]. This technique has been used to evaluate oesophageal-glottic reflexes as well as reflexive pharyngeal swallowing in neonates $[131,132]$. Further development of this technique may allow for the systematic study of pharyngeal and glottic reflexes that favour airway protection in infants in a noninvasive way.

As the lung is the end-organ of disease in aspiration, determining a valid BAL biomarker for CPA is of interest 


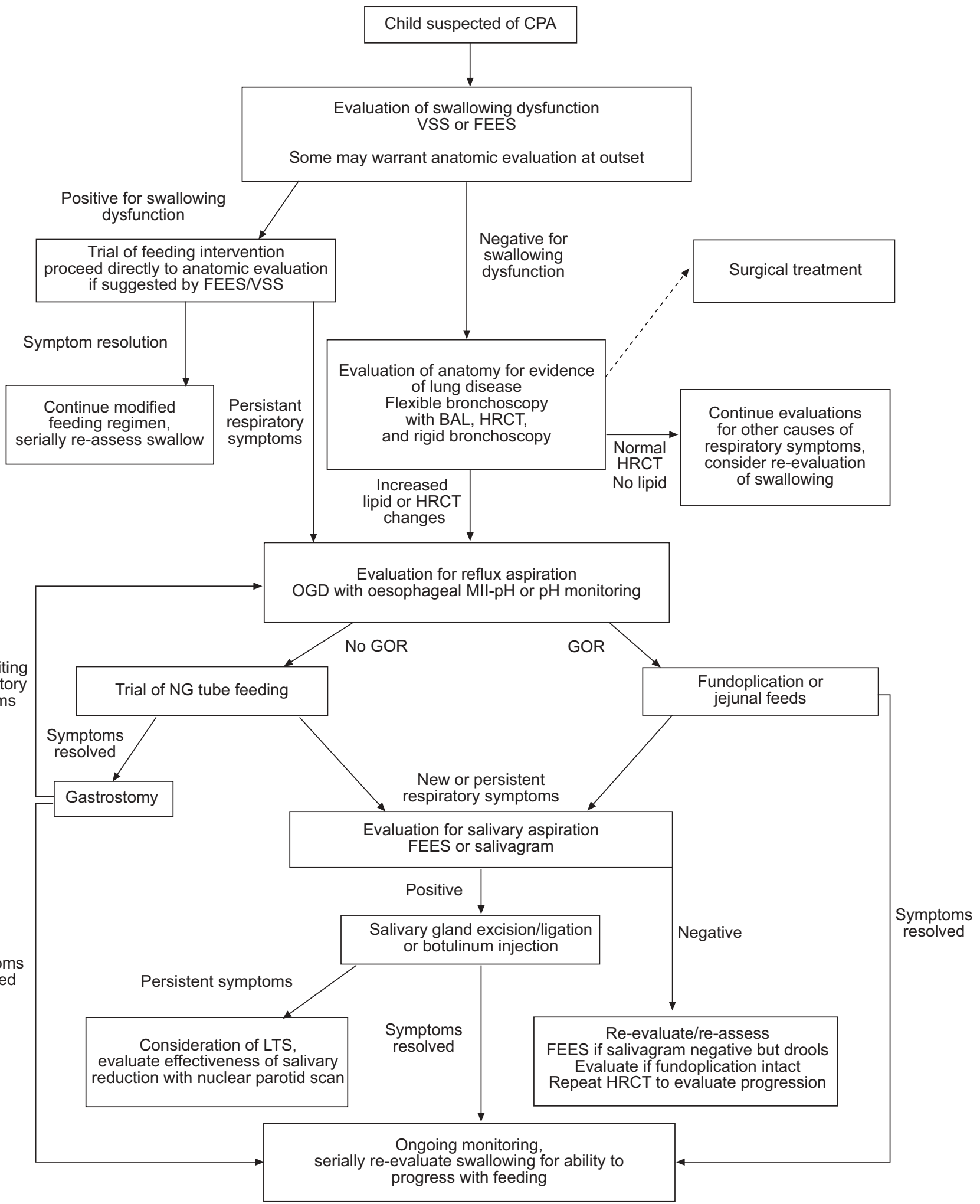

FIGURE 1. A diagnosis and treatment algorithm for chronic pulmonary aspiration (CPA) in children. VSS: videofluoroscopic swallow study; FEES: fibreoptic-endoscopic evaluation of swallowing; BAL: bronchoalveolar lavage; HRCT: high-resolution computed tomography; OGD: oesophagogastroduodenoscopy; MIl: multichannel intraluminal impedance; GOR: gastro-oesophageal reflux; NG: nasogastric; LTS: laryngotracheal separation. 
and several have been investigated. Gastric pepsin assays on BAL fluid have been evaluated as a specific test of aspiration due to GOR [133-135]. KRISHNAN et al. [133] detected pepsin in tracheal aspirates in $26 \%$ of children with GOR, $83.8 \%$ of those with both GOR and chronic respiratory symptoms, and in no children with neither GOR nor respiratory symptoms. WARD et al. [135] found pepsin in BAL of all lung-transplant recipients but not in controls. Immunocytochemical staining for $\alpha$-lactalbumin and $\beta$-lactoglobulin showed good specificity and sensitivity in a mouse model [136] but a follow-up clinical pilot study generated confusing results [137]. There has also been a preliminary study of the use of polystyrene microspheres as a potential test of aspiration [138]. After a single instillation into the tracheas of hamsters, microspheres were identifiable in alveolar macrophages through the end of the study (90 days). The half-life for disappearance was 10 days. The fact that this substance has no endogenous source makes it attractive. The use of such a material could potentially distinguish between aspirators and nonaspirators, as well as between direct aspiration and reflux aspiration.

\section{CONCLUSION}

Despite the use of multiple diagnostic techniques, characterising the presence or absence of aspiration, what a child may be aspirating and under what circumstances this child might be aspirating is extremely challenging. This uncertainty is of great consequence given the outcome of unrecognised progressive lung injury and the invasiveness of definitive therapies. Since the 1990s, new diagnostic techniques have been introduced and significant advances in the understanding of dysphagia, gastro-oesophageal reflux and airway protective reflexes have been made. Nevertheless, many children are still not adequately diagnosed or treated for aspiration until permanent lung damage and disability have occurred. Certainly, more research is needed to determine the accuracy of diagnostic methods and appropriateness of interventions. Given the complexity and heterogeneity of children affected, the variable and episodic nature of aspiration and the coexistence of various types of aspiration, conducting such research is exceedingly difficult. Currently, conducting a thorough clinical evaluation, using a multidisciplinary approach and utilising evidence from multiple diagnostic procedures is the best way to provide timely and appropriate care to children with chronic pulmonary aspiration.

\section{ACKNOWLEDGEMENTS}

The authors would like to thank all those involved in the Aerodigestive and Sleep Center at Cincinnati Children's Hospital Medical Center, for the key role they played in the evaluation, management and care of children with aspiration disorders.

\section{REFERENCES}

1 Owayed AF, Campbell DM, Wang EEL. Underlying causes of recurrent pneumonia in children. Arch Pediatr Adolesc Med 2000; 154: 190-194.

2 Lodha R, Puranik M, Natchu UCM, Kabra SK. Recurrent pneumonia in children: clinical profile and underlying causes. Acta Pediatr 2002; 91: 1170-1173.
3 Colombo JL, Sammut PH. Aspiration syndromes. In: Taussig LM, Landau LI, eds. Pediatric Respiratory Medicine. St. Louis, Mosby, 1999; pp. 435-443.

4 Murray LN, Guarisco JL. Chronic aspiration in children. J La State Med Soc 1997; 149: 462-467.

5 Bauer ML, Figueroa-Colon R, Georgeson K, Young DW. Chronic pulmonary aspiration in children. South Med J 1993; 86: 789-795.

6 Gillies JD, Seshia SS. Vegetative state following coma in childhood: evolution and outcome. Dev Med Child Neurol 1980; 22: 642-648.

7 Huxley EJ, Viroslav J, Gray WR, Pierce AK. Pharyngeal aspiration in normal adults and patients with depressed consciousness. Am J Med 1978; 64: 564-568.

8 Gleeson K, Eggli DF, Maxwell SL. Quantitative aspiration during sleep in normal subjects. Chest 1997; 111: 1266-1272.

9 Sheikh S, Allen E, Shell R, et al. Chronic aspiration without gastroesophageal reflux as a cause of chronic respiratory symptoms in neurologically normal infants. Chest 2001; 120: 1190-1195.

10 Orenstein SR. An overview of reflux-associated disorders in infants: apnea, laryngospasm, and aspiration. Am J Med 2001; 111: Suppl. 8A, 60S-63S.

11 Berquist WE, Rachelefsky GS, Kadden M, et al. Gastroesophageal reflux-associated recurrent pneumonia and chronic asthma in children. Pediatrics 1981; 68: 29-35.

12 Chen $\mathrm{PH}$, Chang MH, Hsu SC. Gastroesophageal reflux in children with chronic recurrent bronchopulmonary infection. J Pediatr Gastroenterol Nutr 1991; 13: 16-22.

13 Harding SM. Recent clinical investigations examining the association of asthma and gastroesophageal reflux. Am J Med 2003; 115: Suppl. 3A, 39S-44S.

14 Rudolph CD. Supraesophageal complications of gastroesophageal reflux in children: challenges in diagnosis and treatment. Am J Med 2003; 115: Suppl. 3A, 150S$156 \mathrm{~S}$.

15 Weinberger M. Gastroesophageal reflux disease is not a significant cause of lung disease in children. Pediatr Pulmonol Suppl 2004; 26: 197-200.

16 Jack CI, Calverley PM, Donnelly RJ, et al. Simultaneous tracheal and oesophageal $\mathrm{pH}$ measurements in asthmatic patients with gastro-oesophageal reflux. Thorax 1995; 50: 201-204.

17 Donnelly RJ, Berrisford RG, Jack CI, Tran JA, Evans CC. Simultaneous tracheal and esophageal $\mathrm{pH}$ monitoring: investigating reflux-associated asthma. Ann Thorac Surg 1993; 56: 1029-1033.

18 Phua SY, McGarvey LP, Ngu MC, Ing AJ. Patients with gastro-oesophageal reflux disease and cough have impaired laryngopharyngeal mechanosensitivity. Thorax 2005; 60: 488-491.

19 Morton RE, Wheatley R, Minford J. Respiratory tract infections due to direct and reflux aspiration in children with severe neurodisability. Dev Med Child Neurol 1999; 41: 329-334.

20 Mendelson CL. The aspiration of stomach contents into the lungs during obstetric anesthesia. Am J Obstet Gynecol 1946; 52: 191-204.

21 Schwartz DJ, Wynne JW, Gibbs CP, Hood CI, Kuck EJ. The pulmonary consequences of aspiration of gastric 
contents at $\mathrm{pH}$ values greater than 2.5. Am Rev Respir Dis 1980; 121: 119-126.

22 Stein MR. Possible mechanisms of influence of esophageal acid on airway hyperresponsiveness. Am J Med 2003;115: Suppl. 3A, 55S-59S.

23 Brook I, Finegold SM. Bacteriology of aspiration pneumonia in children. Pediatrics 1980; 65: 1115-1120.

24 Hussein I, Kershaw AE, Tahmassebi JF, Fayle SA. The management of drooling in children and patients with mental and physical disabilities: a literature review. Int J Paediatr Dent 1998; 8: 3-11.

25 Rossi UG, Owens CM. The radiology of chronic lung disease in children. Arch Dis Child 2005; 90: 601-607.

26 Kuhn JP, Brody AS. High-resolution CT of pediatric lung disease. Radiol Clin North Am 2002; 40: 89-110.

27 Eastham KM, Fall AJ, Mitchell L, Spencer DA. The need to redefine non-cystic fibrosis bronchiectasis in childhood. Thorax 2004; 59: 324-327.

28 DeMatteo C, Matovich D, Hjartarson A. Comparison of clinical and videofluoroscopic evaluation of children with feeding and swallowing difficulties. Dev Med Child Neurol 2005; 47: 149-157.

29 Martin-Harris B, Logemann JA, McMahon S, Schleicher M, Sandidge J. Clinical utility of the modified barium swallow. Dysphagia 2000; 15: 136-141.

30 Schurr MJ, Ebner KA, Maser AL, Sperling KB, Helgerson RB, Harms B. Formal swallowing evaluation and therapy after traumatic brain injury improves dysphagia outcomes. J Trauma 1999; 46: 817-823.

31 Logemann JA. Role of the modified barium swallow in management of patients with dysphagia. Otolaryngol Head Neck Surg 1997; 116: 335-338.

32 Croghan JE, Burke EM, Caplan S, Denman S. Pilot study of 12-month outcomes of nursing home patients with aspiration on videofluoroscopy. Dysphagia 1994; 9: 141-146.

33 Aviv JE, Sacco RL, Mohr JP, et al. Laryngopharyngeal sensory testing with modified barium swallow as predictors of aspiration pneumonia after stroke. Laryngoscope 1997; 107: 1254-1260.

34 Stoeckli SJ, Huisman TA, Seifert B, Martin-Harris BJ. Interrater reliability of videofluoroscopic swallow evaluation. Dysphagia 2003; 18: 53-57.

35 Kuhlemeier KV, Yates P, Palmer JB. Intra- and interrater variation in the evaluation of videofluorographic swallowing studies. Dysphagia 1998; 13: 142-147.

36 Ekberg O, Nylander G, Fork FT, Sjoberg S, BirchIensen $\mathrm{M}$, Hillarp B. Interobserver variability in cineradiographic assessment of pharyngeal function during swallow. Dysphagia 1988; 3: 46-48.

37 Langmore SE, Schatz K, Olsen N. Fiberoptic endoscopic examination of swallowing safety: a new procedure. Dysphagia 1988; 2: 216-219.

38 Leder SB, Sasaki CT, Burrell MI. Fiberoptic endoscopic evaluation of dysphagia to identify silent aspiration. Dysphagia 1998; 13: 19-21.

39 Langmore SE, Schatz K, Olson N. Endoscopic and videofluoroscopic evaluations of swallowing and aspiration. Ann Otol Rhinol Laryngol 1991; 100: 678-681.

40 Leder SB, Karas DE. Fiberoptic endoscopic evaluation of swallowing in the pediatric population. Laryngoscope 2000; 110: 1132-1136.
41 Aviv JE. Prospective, randomized outcome study of endoscopy versus modified barium swallow in patients with dysphagia. Laryngoscope 2000; 110: 563-574.

42 Colodny N. Interjudge and intrajudge reliabilities in fiberoptic endoscopic evaluation of swallowing (FEES) using the penetration-aspiration scale: a replication study. Dysphagia 2002; 17: 308-315.

43 Link DT, Willging JP, Miller CK, Cotton RT, Rudolph CD. Pediatric laryngopharyngeal sensory testing during flexible endoscopic evaluation of swallowing: feasible and correlative. Ann Otol Rhinol Laryngol 2000; 109: 899-905.

44 Colombo JL, Hallberg TK. Recurrent aspiration in children: lipid-laden alveolar macrophage quantitation. Pediatr Pulmonol 1987; 3: 86-89.

45 Bauer ML, Lyrene RK. Chronic aspiration in children: evaluation of the lipid-laden macrophage index. Pediatr Pulmonol 1999; 28: 94-100.

46 Knauer-Fischer S, Ratjen F. Lipid-laden macrophages in bronchoalveolar lavage fluid as a marker for pulmonary aspiration. Pediatr Pulmonol 1999; 27: 419-422.

47 Kazachkov MY, Muhlebach MS, Livasy CA, Noah TL. Lipid-laden macrophage index and inflammation in bronchoalveolar lavage fluids in children. Eur Respir J 2001; 18: 790-795.

48 Wright JR, Youmans DC. Degradation of surfactant lipids and surfactant protein A by alveolar macrophages in vitro. Am J Physiol 1995; 268: L772-L780.

49 Kajetanowicz A, Stinson D, Laybolt KS, Resch L. Lipidladen macrophages in the tracheal aspirate of neonates receiving intralipid: a pilot study. Pediatr Pulmonol 1999; 28: 101-108.

50 Wang JY, Kuo PH, Jan IS, Lee LN, Yang PC. Serial analysis of fat-containing macrophages in bronchoalveolar lavage fluid in a patient with fat embolism syndrome. J Formos Med Assoc 2001; 100: 557-560.

51 Wright BA, Jeffrey PH. Lipoid pneumonia. Semin Respir Infect 1990; 5: 314-321.

52 Moran JR, Block SM, Lyerly AD, Brooks LE, Dillard RG. Lipid-laden alveolar macrophage and lactose assay as markers of aspiration in neonates with lung disease. J Pediatr 1988; 112: 643-645.

53 Ahrens P, Noll C, Kitz R, Willigens P, Zielen S, Hofmann D. Lipid-laden alveolar macrophages (LLAM): a useful marker of silent aspiration in children. Pediatr Pulmonol 1999; 28: 83-88.

54 Sacco O, Fregonese B, Silvestri M, Sabatini F, Mattioli G, Rossi GA. Bronchoalveolar lavage and esophageal $\mathrm{pH}$ monitoring data in children with "difficult to treat" respiratory symptoms. Pediatr Pulmonol 2000; 30: 313-319.

55 Ding Y, Simpson PM, Schellhase DE, Tryka AF, Ding L, Parham DM. Limited reliability of lipid-laden macrophage index restricts its use as a test for pulmonary aspiration: comparison with a simple semiquantitiative assay. Pediatr Dev Pathol 2002; 5: 551-558.

56 Colombo JL, Hallberg TK, Sammut PH. Time course of lipid-laden pulmonary macrophages with acute and recurrent milk aspiration in rabbits. Pediatr Pulmonol 1992; 12: 95-98.

57 Shay SS, Johnson LF, Richter JE. Acid rereflux: a review, emphasizing detection by impedance, manometry, and 
scintigraphy, and the impact on acid clearing pathophysiology as well as interpreting the $\mathrm{pH}$ record. Dig Dis Sci 2003; 48: 1-9.

58 Wenzl TG, Moroder C, Trachterna M, et al. Esophageal $\mathrm{pH}$ monitoring and impedance measurement: a comparison of two diagnostic tests for gastroesophageal reflux. $J$ Pediatr Gastroenterol Nutr 2002; 34: 519-523.

59 Skopnik H, Silny J, Heiber O, Schulz J, Rau G, Heimann G. Gastroesophageal reflux in infants: evaluation of a new intraluminal impedance technique. J Pediatr Gastroenterol Nutr 1996; 23: 591-598.

60 Tutuian R, Castell DO. Use of multichannel intraluminal impedance to document proximal esophageal and pharyngeal nonacidic reflux episodes. Am J Med 2003; 115: Suppl. 3A,119S-123S.

61 Kawamura O, Aslam M, Rittmann T, Hofmann C, Shaker R. Physical and $\mathrm{pH}$ properties of gastroesophagopharyngeal refluxate: a 24-hour simultaneous ambulatory impedance and $\mathrm{pH}$ monitoring study. Am J Gastroenterol 2004; 99: 1000-1010.

62 Wenzl TG, Silny J, Schenke S, Peschgens T, Heimann G, Skopnik H. Gastroesophageal reflux and respiratory phenomena in infants: status of the intraluminal impedance technique. J Pediatr Gastroenterol Nutr 1999; 28: 423-428.

63 McVeagh P, Howman-Giles R, Kemp A. Pulmonary aspiration studied by radionuclide milk scanning and barium swallow roentgenography. Am J Dis Child 1987; 141: 917-921.

64 Fawcett HD, Hayden CK, Adams JC, Swischuk LE. How useful is gastroesophageal reflux scintigraphy in suspected childhood aspiration? Pediatr Radiol 1988; 18: 311-313.

65 Silver KH, Van Nostrand D. The use of scintigraphy in the management of patients with pulmonary aspiration. Dysphagia 1994; 9: 107-115.

66 Baikie G, South MJ, Reddihough DS, et al. Agreement of aspiration tests using barium videofluoroscopy, salivagram, and milk scan in children with cerebral palsy. Dev Med Child Neurol 2005; 47: 86-93.

67 Heyman S, Respondek M. Detection of pulmonary aspiration in children by radionuclide "salivagram". J Nucl Med 1989; 30: 697-699.

68 Bar-Sever Z, Connolly LP, Treves ST. The radionuclide salivagram in children with pulmonary disease, a high risk of aspiration, Pediatr Radiol 1995; 25: Suppl. 1, S180-S183.

69 Levin K, Colon A, DiPalma J, Fitzpatrick S. Using the radionuclide salivagram to detect pulmonary aspiration and esophageal dysmotility. Clin Nuc Med 1993; 18: 110-114.

70 Cook SP, Lawless S, Mandell GA, Reilly JS. The use of the salivagram in the evaluation of severe and chronic aspiration. Int J Pediatr Otorhinolaryngol 1997; 41: 353-361.

71 Finder JD, Yellon R, Charron M. Successful management of tracheotomized patients with chronic saliva aspiration by use of constant positive airway pressure. Pediatrics 2001; 107: 1343-1345.

72 Murray J, Langmore SE, Ginsberg S, Dostie A. The significance of accumulated oropharyngeal secretions and swallowing frequency in predicting aspiration. Dysphagia 1996; 11: 99-103.

73 Perlman PW, Cohen MA, Setzen M, et al. The risk of aspiration of pureed food as determined by flexible endoscopic evaluation of swallowing with sensory testing. Otolaryngol Head Neck Surg 2004; 130: 80-83.

74 Setzen M, Cohen MA, Perlman PW, et al. The association between laryngopharyngeal sensory deficits, pharyngeal motor function, and the prevalence of aspiration with thin liquids. Otolaryngol Head Neck Surg 2003; 128: 99-102.

75 Thompson DM. Laryngopharyngeal sensory testing and assessment of airway protection in pediatric patients. Am J Med 2003;115: Suppl. 3A, 166S-168S.

76 Brady SL, Hildner CD, Hutchins BF. Simultaneous videofluoroscopic swallow study and modified Evans blue dye procedure: an evaluation of blue dye visualization in cases of known aspiration. Dysphagia 1999; 14: 146-149.

77 Peruzzi WT, Logemann JA, Currie D, Moen SG. Assessment of aspiration in patients with tracheostomies: comparison of the bedside colored dye assessment with videofluoroscopic examination. Respir Care 2001; 46: 243-247.

78 Donzelli J, Brady S, Wesling M, Craney M. Simultaneous modified Evans blue dye procedure and video nasal endoscopic evaluation of the swallow. Laryngoscope 2001; 111: 1746-1750.

79 O'Neil-Pirozzi TM, Lisiecki DJ, Jack Momose K, Connors JJ, Milliner MP. Simultaneous modified barium swallow and blue dye tests: a determination of the accuracy of blue dye test aspiration findings. Dysphagia 2003; 18: 32-38.

80 Belafsky PC, Blumenfeld L, LePage A, Nahrstedt K. The accuracy of the modified Evan's blue dye test in predicting aspiration. Laryngoscope 2003; 113: 1969-1972.

81 Burklow KA, Phelps AN, Schultz JR, McConnell K, Rudolph C. Classifying complex pediatric feeding disorders. J Pediatr Gastroenterol Nutr 1998; 27: 143-147.

82 Muraji T, Takamizawa S, Satoh S, et al. Congenital cricopharyngeal achalasia: diagnosis and surgical management. J Pediatr Surg 2002; 37: E12.

83 Mollitt DL, Golladay ES, Seibert JJ. Symptomatic gastroesophageal reflux following gastrostomy in neurologically impaired patients. Pediatrics 1985; 75: 1124-1126.

84 Jolley SG, Smith EI, Tunell WP. Protective antireflux operation with feeding gastrostomy. Experience with children. Ann Surg 1985; 201: 736-740.

85 Langer JC, Wesson DE, Ein SH, et al. Feeding gastrostomy in neurologically impaired children: is an antireflux procedure necessary? J Pediatr Gastroenterol Nutr 1988; 7: 837-841.

86 Wheatley MJ, Wesley JR, Tkach DM, Coran AG. Longterm follow-up of brain-damaged children requiring feeding gastrostomy: should an antireflux procedure always be performed? J Pediatr Surg 1991; 26: 301-305.

87 Heine RG, Reddihough DS, Catto-Smith AG. Gastrooesophageal reflux and feeding problems after gastrostomy in children with severe neurological impairment. Dev Med Child Neurol 1995; 37: 320-329.

88 Isch JA, Rescorla FJ, Scherer LR 3rd, West KW, Grosfeld JL. The development of gastroesophageal reflux after 
percutaneous endoscopic gastrostomy. J Pediatr Surg 1997; 32: 321-322.

89 Sulaeman E, Udall JN Jr, Brown RF, et al. Gastroesophageal reflux and nissen fundoplication following percutaneous endoscopic gastrostomy in children. $J$ Pediatr Gastroenterol Nutr 1998; 26: 269-273.

90 Puntis JW, Thwaites R, Abel G, Stringer MD. Children with neurological disorders do not always need fundoplication concomitant with percutaneous endoscopic gastrostomy. Dev Med Child Neurol 2000; 42: 97-99.

91 Hament JM, Bax NM, van der Zee DC, De Schryver JE, Nesselaar C. Complications of percutaneous endoscopic gastrostomy with or without concomitant antireflux surgery in 96 children. J Pediatr Surg 2001; 36: 1412-1415.

92 Burd RS, Price MR, Whalen TV. The role of protective antireflux procedures in neurologically impaired children: a decision analysis. J Pediatr Surg 2002; 37: 500-506.

93 Wenzl TG, Schneider S, Scheele F, Silny J, Heimann G, Skopnik H. Effects of thickened feeding on gastroesophageal reflux in infants: a placebo-controlled crossover study using intraluminal impedance. Pediatrics 2003; 111: e355-e359.

94 Chicella MF, Batres LA, Heesters MS, Dice JE. Prokinetic drug therapy in children: a review of current options. Ann Pharmacother 2005; 39: 706-711.

$95 \mathrm{Ng}$ SC, Gomez JM, Rajaduri VS, Saw SM, Quark SH. Establishing enteral feeding in preterm infants with feeding intolerance: a randomized controlled study of low-dose erythromycin. J Pediatr Gastroenterol Nutr 2003; 37: 554-558.

96 Stenson BJ, Middlemist L, Lyon AJ. Influence of erythromycin on establishment of feeding preterm infants: observations from a randomized controlled trial. Arch Dis Child Fetal Neonatal Ed 1998; 79: F212-F214.

97 Oei J, Lui K. A placebo-controlled trial of low-dose erythromycin to promote feed tolerance in preterm infants. Acta Pediatr 2001; 90: 904-908.

98 Costalos C, Gounaris A, Varhalama E, Kokori F, Alexiou N, Kolovou E. Erythromycin as a prokinetic agent in preterm infants. J Pediatr Gastroenterol Nutr 2002; 34: 13-15.

99 Di Lorenzo C, Flores AF, Tomomasa T, Hyman PE. Effect of erythromycin on antroduodenal motility in children with chronic functional gastrointestinal symptoms. Dig Dis Sci 1994; 39: 1399-1404.

100 Pritchard DS, Baber N, Stephenson T. Should domperidone be used for the treatment of gastro-oesophageal reflux in children? Systematic review of randomized controlled trials in children aged 1 month to 11 years old. Br J Clin Pharmacol 2005; 59: 725-729.

101 Jolley SG, Herbst JJ, Johnson DG, Matlak ME, Book LS. Surgery in children with gastroesophageal reflux and respiratory symptoms. J Pediatr 1980; 96: 194-198.

102 Mattioli G, Sacco O, Repetto P, et al. Necessity for surgery in children with gastrooesophageal reflux and supraoesophageal symptoms. Eur J Pediatr Surg 2004; 14: 7-13.

103 Kawahara H, Okuyama H, Kubota A, et al. Can laparoscopic antireflux surgery improve the quality of life in children with neurologic and neuromuscular handicaps? J Pediatr Surg 2004; 39: 1761-1764.
104 Esposito C, Langer JC, Schaarschmidt K, et al. Laparoscopic antireflux procedures in the management of gastroesophageal reflux following esophageal atresia repair. J Pediatr Gastroenterol Nutr 2005; 40: 349-351.

105 Kazerooni NL, VanCamp J, Hirschl RB, Drongowski RA, Coran AG. Fundoplication in 160 children under 2 years of age. J Pediatr Surg 1994; 29: 677-681.

106 Ramachandran V, Ashcraft KW, Sharp RJ, et al. Thal fundoplication in neurologically impaired children. $J$ Pediatr Surg 1996; 31: 819-822.

107 Rothenberg SS. Experience with 220 consecutive laparoscopic nissen fundoplications in infants and children. $J$ Pediatr Surg 1998; 33: 274-278.

108 Dalla Vecchia LK, Grosfeld JL, West KW, Rescorla FJ, Scherer LR 3rd, Engum SA. Reoperation after nissen fundoplication in children with gastroesophageal reflux: experience with 130 patients. Ann Surg 1997; 226: 315-323.

109 Wales PW, Diamond IR, Dutta S, et al. Fundoplication and gastrostomy versus image-guided gastrojejunal tube for enteral feeding in neurologically impaired children with gastroesophageal reflux. J Pediatr Surg 2002; 37: 407-412.

110 Esposito C, Settimi A, Centonze A, Capano G, Ascione G. Laparoscopic-assisted jejunostomy: an effective procedure for the treatment of neurologically impaired children with feeding problems and gastroesophageal reflux. Surg Endosc 2005; 19: 501-504.

111 Islam S, Teitelbaum DH, Buntain WL, Hirschl RB. Esophagogastric separation for failed fundoplication in neurologically impaired children. J Pediatr Surg 2004; 39: 287-291.

112 de Lagausie P, Bonnard A, Schultz A, et al. Reflux in esophageal atresia, tracheoesophageal cleft, and esophagocoloplasty: Bianchi's procedure as an alternative approach. J Pediatr Surg 2005; 40: 666-669.

113 Mier RJ, Bachrach SJ, Lakin RC, Barker T, Childs J, Moran M. Treatment of sialorrhea with glycopyrrolate: a double-blind, dose-ranging study. Arch Pediatr Adolesc Med 2000; 154: 1214-1218.

114 Blasco PA, Stansbury JC. Glycopyrrolate treatment of chronic drooling. Arch Pediatr Adolesc Med 1996; 150: 932-935.

115 Stern LM. Preliminary study of glycopyrrolate in the management of drooling. J Paediatr Child Health 1997; 33: 52-54.

116 Jongerius $\mathrm{PH}$, van den Hoogen FJ, van Limbeek J, Gabreels FJ, van Hulst K, Rotteveel JJ. Effect of botulinum toxin in the treatment of drooling: a controlled clinical trial. Pediatrics 2004; 114: 620-627.

117 Savarese R, Diamond M, Elovic E, Millis SR. Intraparotid injection of botulinum toxin $\mathrm{A}$ as a treatment to control sialorrhea in children with cerebral palsy. Am J Phys Med Rehabil 2004; 83: 304-311.

118 Hassin-Baer S, Scheuer E, Buchman AS, Jacobson I, BenZeev B. Botulinum toxin injections for children with excessive drooling. J Child Neurol 2005; 20: 120-123.

119 Gerber ME, Gaugler MD, Myer CM 3rd, Cotton RT. Chronic aspiration in children. When are bilateral submandibular gland excision and parotid duct ligation 
indicated? Arch Otolaryngol Head Neck Surg 1996; 122: 1368-1371.

120 Stern Y, Feinmesser R, Collins M, Shott SR, Cotton RT. Bilateral submandibular gland excision with parotid duct ligation for treatment of sialorrhea in children: long-term results. Arch Otolaryngol Head Neck Surg 2002; 128: 801-803.

121 Klem C, Mair EA. Four-duct ligation: a simple and effective treatment for chronic aspiration from sialorrhea. Arch Otolaryngol Head Neck Surg 1999; 125: 796-800.

122 Shirley WP, Hill JS, Woolley AL, Wiatrak BJ. Success and complications of four-duct ligation for sialorrhea. Int $J$ Pediatr Otorhinolaryngol 2003; 67: 1-6.

123 Elpern EH, Scott MG, Petro L, Ries MH. Pulmonary aspiration in mechanically ventilated patients with tracheostomies. Chest 1994; 105: 563-566.

124 Abraham SS, Wolf EL. Swallowing physiology of toddlers with long-term tracheostomies: a preliminary study. Dysphagia 2000; 15: 206-212.

125 Leder SB, Ross DA. Investigation of the causal relationship between tracheotomy and aspiration in the acute care setting. Laryngoscope 2000; 110: 641-644.

126 Cook SP, Lawless ST, Kettrick R. Patient selection for primary laryngotracheal separation as treatment of chronic aspiration in the impaired child. Int J Pediatr Otorhinolaryngol 1996; 38: 103-113.

127 Takamizawa S, Tsugawa C, Nishijima E, Muraji T, Satoh S. Laryngotracheal separation for intractable aspiration pneumonia in neurologically impaired children: experience with 11 cases. J Pediatr Surg 2003; 38: 975-977.

128 Hafidh MA, Young O, Russell JD. Intractable pulmonary aspiration in children: which operation? Int J Pediatr Otorinolaryngol 2006; 70: 19-25.

129 Eibling DE, Synderman CH, Eibling C. Laryngotracheal separation for intractable aspiration for intractable aspiration: a retrospecitve review of 34 patients. Laryngoscope 1995; 105: 83-85.

130 Jadcherla SR, Gupta A, Stoner E, Coley B, Wiet G, Shaker R. Novel non-invasive technique for evaluation of glottis motion in infants and children: comparison of oltrasonography (USG) and transnasal endoscopic approach. Gastroenterology 2005; 128: Suppl. 2, A300.

131 Jadcherla SR, Gupta A, Stoner E, Fernandez S, Shaker R. Identification of reflexive pharyngeal swallowing (RPS) and pharyngo-UES contractile reflex (PUCR) in healthy human neonates. Gastroenterology 2005; 128: Suppl. 2, A409.

132 Jadcherla SR, Gupta A, Stoner E, Coley B, Shaker R. Characterization of esophago-glottal closure reflex (EGCR) in healthy neonates using a novel non-invasive ultrasonography of glottis (USG) technique concurrent with esophageal stimulation. Gastroenterology 2005; 128: Suppl. 2, A410.

133 Krishnan U, Mitchell JD, Messina I, Day AS, Bohane TD. Assay of tracheal pepsin as a marker of reflux aspiration. J Pediatr Gastroenterol Nutr 2002; 35: 303-308.

134 Potluri S, Friedenberg F, Parkman HP, et al. Comparison of a salivary/sputum pepsin assay with 24-hour esophageal $\mathrm{pH}$ monitoring for detection of gastric reflux into the proximal esophagus, oropharynx, and lung. Dig Dis Sci 2003; 48: 1813-1817.

135 Ward C, Forrest IA, Brownlee IA, et al. Pepsin like activity in bronchoalveolar lavage fluid is suggestive of gastric aspiration in lung allografts. Thorax 2005; 60: 872-874.

136 Elidemir O, Fan LL, Colasurdo GN. A novel diagnostic method for pulmonary aspiration in a murine model: immunocytochemical staining of milk proteins in alveolar macrophages. Am J Respir Crit Care Med 2000; 161: 622-626.

137 Miller J, Colasurdo GN, Khan AM, et al. Immunocytochemical detection of milk proteins in tracheal aspirates of ventilated infants: a pilot study. Pediatr Pulmonol 2002; 34: 369-374.

138 Avital A, Shapiro E, Doviner V, et al. Polystyrene microspheres as a specific marker for the diagnosis of aspiration in hamsters. Am J Respir Crit Care Med 2002; 27: 511-514. 